\title{
Multicausal analysis on psychosocial and lifestyle factors among patients undergoing assisted reproductive therapy - with special regard to self-reported and objective measures of pre-treatment habitual physical activity
}

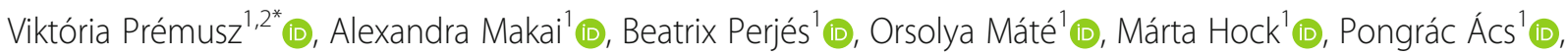
Miklós Koppán ${ }^{3}$ (D) József Bódis ${ }^{2,3}$ (D) Ákos Várnagy ${ }^{2,3+}$ (D) and Kinga Lampek ${ }^{1 \dagger}$ (D)

\begin{abstract}
Background: National, regional and global trends in prevalence of infertility indicate its public health importance, however it effects various life dimensions of individuals and couples as well. Lifestyle habits may counteract with these factors. The aim of the study was the multicausal analysis of psychosocial and lifestyle factors undergoing assisted reproductive therapy (ART) with special regard to pre-treatment habitual physical activity (PA).

Methods: In a cross-sectional, observational cohort study on ART patients ( $N=60$, age $34.6 \pm 5.2$ years, BMI $24.2 \pm$ $4.9 \mathrm{~kg} / \mathrm{m}^{2}$ ) with follow up on outcome measures a detailed description was given on PA patterns (ActriGraph GT3X, GPAQ-H) and on general and infertility related distress (BDI-13, FPI).

Results: Respondents reported normal mood state (BDI-13) but moderately high infertility-related distress (FPI) in Social- and very high distress in Sexual Concern. It was revealed that time spent with recreational PA (RPA) could counteract with infertility-related distress (Social Concern $R=-0.378, p=0.013$; Relationship Concern $R=-0.365, p=0.019$ ). In the presence of clinical pregnancy GPAQ-H RPA MET was significantly higher $(p=0.048)$, in the non-pregnant group cumulative values and work-related PA were higher. Correlations could be found between RPA time and the number of oocytes $(R=0.315, p=0.045)$, matured oocytes $(R=0.339, p=0.030)$ and embryos $(R=0.294, p=0.062)$ by women who reached at least 150 min RPA (GPAQ-H). Multivariate linear regression revealed that the number of oocytes was positively influenced by the GPAQ-H recreation MET $\left(R^{2}=0.367 ; \mathrm{F}=10.994, p=0.004 ; \mathrm{B}=0.005, p=0.004, \mathrm{~B}\right.$ Constant $\left.=4.604\right)$.

\footnotetext{
*Correspondence: premusz.viktoria@pte.hu

${ }^{\dagger}$ Ákos Várnagy and Kinga Lampek contributed equally to this work.

'Faculty of Health Sciences, University of Pécs, Vorosmarty u. 4, Pécs 7621, Hungary

${ }^{2}$ MTA-PTE Human Reproduction Scientific Research Group, University of Pécs, Édesanyák u. 17, Pécs H-7624, Hungary

Full list of author information is available at the end of the article
}

(c) The Author(s). 2021 Open Access This article is licensed under a Creative Commons Attribution 4.0 International License, which permits use, sharing, adaptation, distribution and reproduction in any medium or format, as long as you give appropriate credit to the original author(s) and the source, provide a link to the Creative Commons licence, and indicate if changes were made. The images or other third party material in this article are included in the article's Creative Commons licence, unless indicated otherwise in a credit line to the material. If material is not included in the article's Creative Commons licence and your intended use is not permitted by statutory regulation or exceeds the permitted use, you will need to obtain permission directly from the copyright holder. To view a copy of this licence, visit http://creativecommons.org/licenses/by/4.0/ The Creative Commons Public Domain Dedication waiver (http://creativecommons.org/publicdomain/zero/1.0/) applies to the data made available in this article, unless otherwise stated in a credit line to the data. 


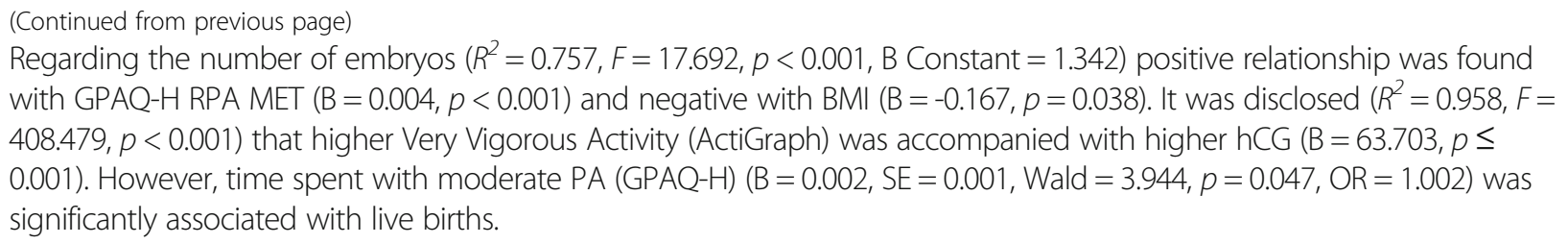

Conclusions: Amount of PA alone did not have a positive effect on outcome of ART. Type and intensity seemed to be more significant. Existing differences in response to infertility due to recreational PA suggest the importance of the development of a specific intervention. The robust overestimation of PA in self-reports highlights the need to improve physical literacy of women undergoing ART.

Keywords: Physical activity, GPAQ, Accelerometer, Assisted reproduction, IVF, Outcomes, Psychosocial factors, Lifestyle, Pregnancy rate, Live birth

\section{Background}

National, regional and global trends in prevalence of infertility indicate its public health importance [1-7]. Multiple definitions on infertility are used in parallel from demographic $[1,8]$ or epidemiological point of view [9], or it could even be considered as a disability [10]. The current study is based on the clinical definition which describes infertility as "a disease of the reproductive system defined by the failure to achieve a clinical pregnancy after 12 months or more of regular unprotected sexual intercourse" following the International Classification of Diseases (ICD-11) [11].

Infertility could specifically affect various life dimensions of individuals or couples, such as depression, anxiety, social isolation, sexual dysfunction, psychological and social distress (PSD), and poorer marital adjustment [12-15]. It has been hypothesized that depression and anxiety may substantially have a negative effect on female reproduction or assisted reproductive treatment (ART) due to hormonal, neuroendocrine, or immunologic functioning and lead to poor outcomes [16-20]. The relationship between psychosocial stress in relation to the success of IVF/ICSI is still under discussion [21, 22]. It was demonstrated that pretreatment levels of perceived anxiety and depression were significantly related to treatment outcome in in vitro fertilization (IVF) [23, 24]. For this reason, it is necessary to explore the fertility related PSD.

Benefits of regular physical activity to maintain physical, mental and social health are not called into question [25-31]. Positive effects on women's health are proven in different contexts [32-35] underlining its importance in pregnancy as well [36-39]. Depending on intensity or duration, certain studies disagree on health effects of exercise or even PA in relation to ART [40-43]. These PA studies primarily focus on outcomes of ART and less on the PSD aspects during the course of the therapy.

Therefore, the aim of the current research was to describe PA and PSD patterns and their combined effects on the course and outcomes of the treatment in ART patients using a multi-causal model.

\section{Methods \\ Study design and sample Study design}

A cross-sectional, observational cohort study was conducted with consecutive sampling at the Assisted Reproduction Unit, Department of Obstetrics and Gynaecology, University of Pécs, Hungary. All female patients with both female and male factors of infertility who were indicated for fertility treatment (IVF/ICSI) were consecutively invited to participate in the study. Participants were recruited according to the date of the fertility consultation. Inclusion criterions were BMI $\geq 18$ $\mathrm{kg} / \mathrm{m}^{2}$ and $\leq 38 \mathrm{~kg} / \mathrm{m}^{2}, 18$ to 40 years of age, having undergone not more than three unsuccessful cycles and no significant health risk relevant to the ART procedure and outcome (metabolic and vascular diseases including diabetes mellitus, metabolic syndrome, fatty liver diseases and atherosclerosis, severe endometriosis (stage III or IV) and/or adenomyosis). Participants were not diagnosed with any mental disorders and had no significant physical or mobility impairments.

Data collection was carried out during the routine examination on the 3rd day of the unstimulated cycles. 62 women participated in the study between December 2018 and June 2019, which means $82.66 \%$ response rate. Self-administered questionnaires were given to participants, who filled them at home in a conventional paperpencil form. Questionnaires were returned on the 21st day of the unstimulated cycles. 2 participants were excluded due to high rate of missing questionnaire data. The selection of the study population including patient recruitment, exclusion criteria, and refusals are presented on the flowchart (Fig. 1.)

\section{General characteristics of the sample}

The major socio-demographic and clinical characteristics of the study population have been presented in Table 1. The data of 60 female patients in reproductive age (34.6 \pm 5.2 years), with mostly normal weight (70.0\%, BMI $18.5-$ 


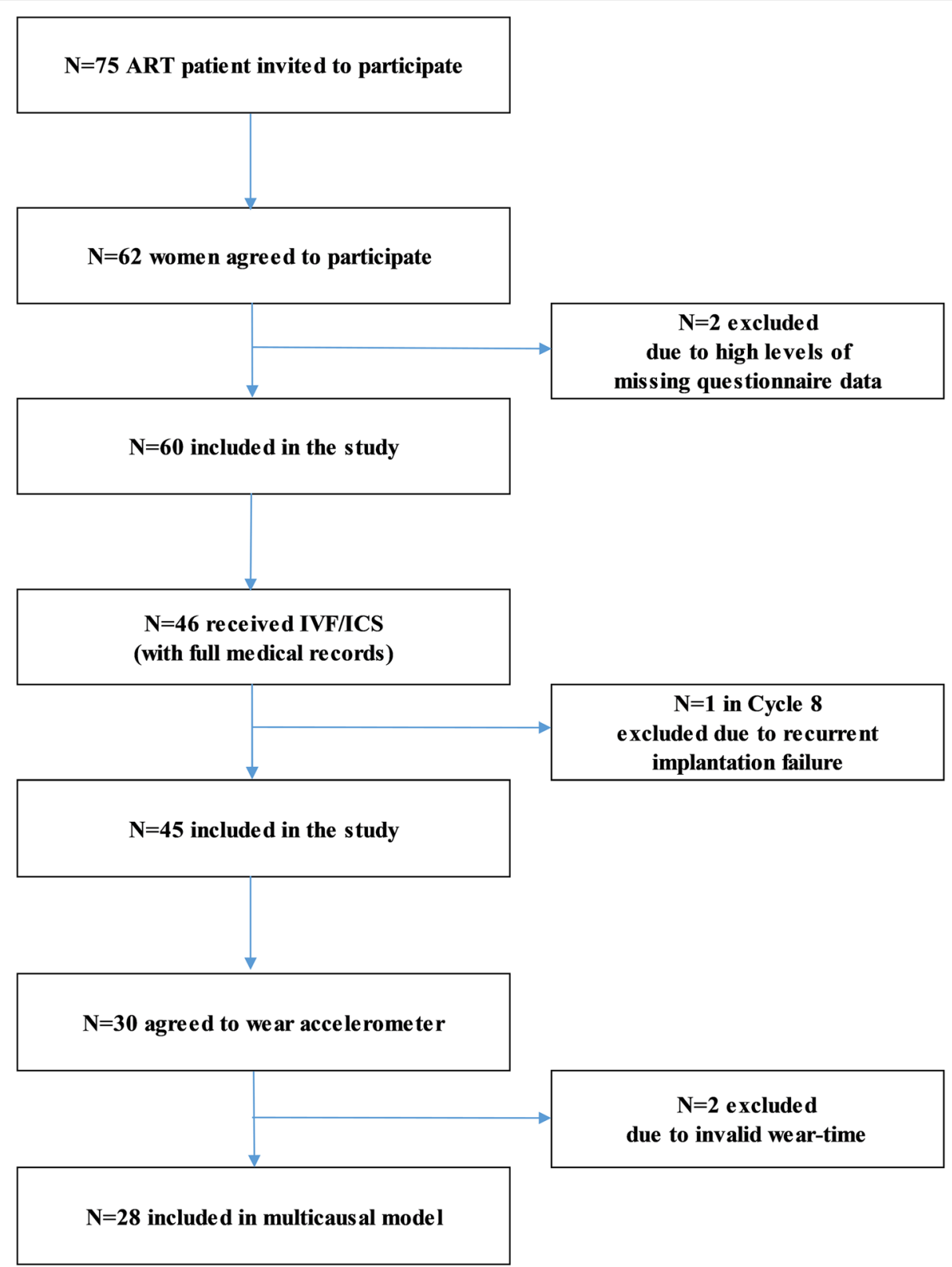

Fig. 1 Flow chart of the study population selection including patient recruitment, exclusion criteria, and refusals

$24.9 \mathrm{~kg} / \mathrm{m}^{2}$ ) were analysed in the study. They were sampled from a larger proportion with higher educational degree $(58.6 \%)$ and with satisfactory economic status (96.6\%). 95.0\% of them worked and $75.0 \%$ had urban residence. Each participant was either married or lived with a partner, and in average the duration of the partnership was 8 years $(7.6 \pm 3.8)$ with an around 5-years-long (59.0 \pm 38.4 month) child-wish. We found various cases of infertility and types of treatments. However, these primarily nulliparous women (84.4\%) typically received IVF/ICSI $(82.3 \%)$ with mostly non-male indication (75.6\%).
Complete clinical data was available regarding $45 \mathrm{IVF} /$ ICSI patients.

76.7\% of the participants rated their physical health particularly good or excellent. In general, they self-reported a health-conscious lifestyle regarding diet, tobacco use and PA, and quality of sleep was satisfactory $(86.2 \%)$ as well. Lifestyle change was also examined, but we cannot report relevant changes back to 5 years ago, since the beginning of ART, or in the current month. $50.0 \%$ of the participants claimed to be physically active, one tenth of them exercised 4-7 times per week (Table 1). 


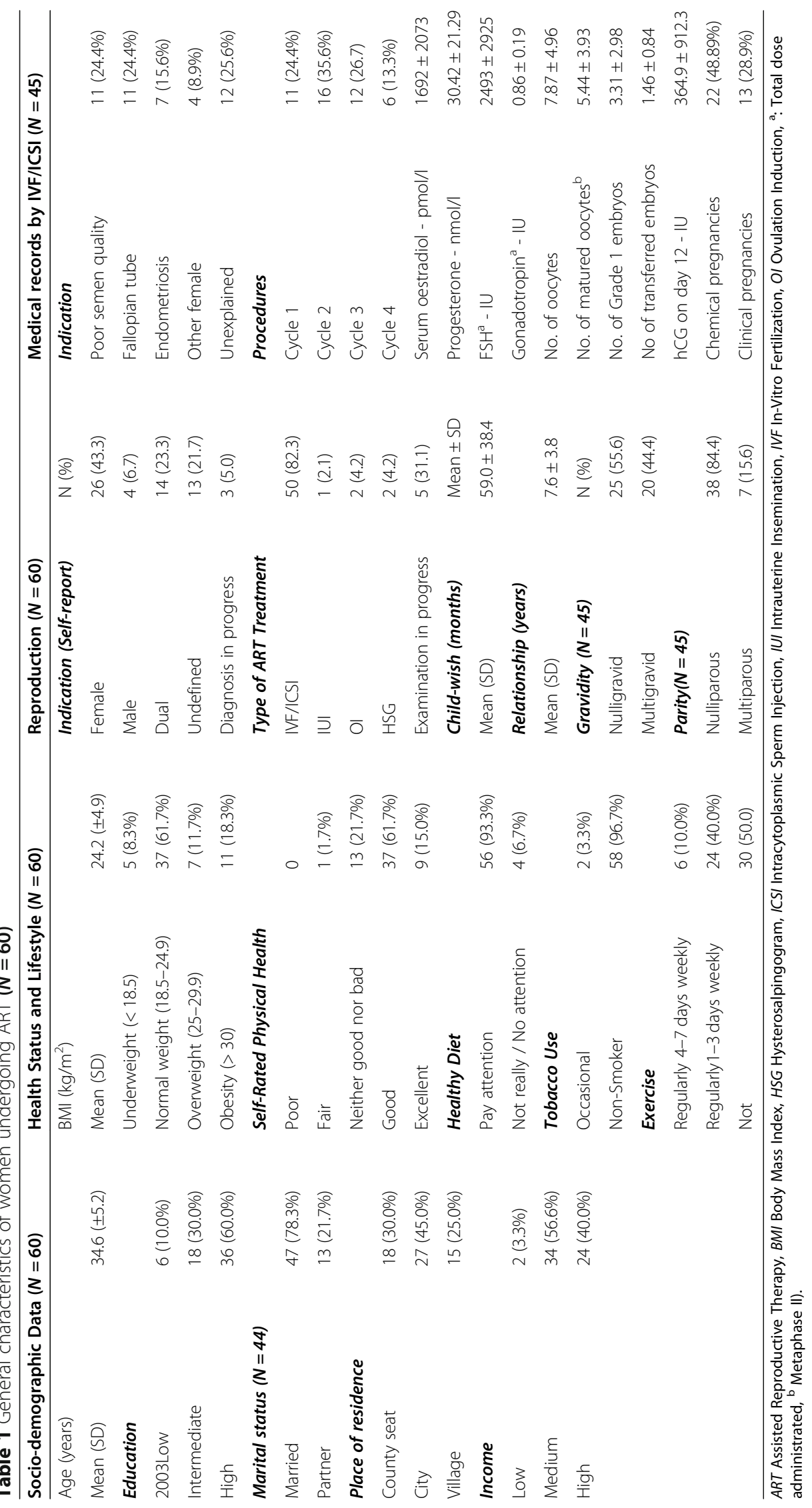




\section{Procedure and measurements Assessment scales}

Socio-demographic characteristics were obtained using questions regarding age, educational level, income, marital status, duration of partnership, duration of infertility, BMI and lifestyle habits.

\section{Assessment of distress}

Beck Depression Inventory (BDI-13) was applied for reporting respondents' mental health status [23, 44-48]. The questionnaire represents how the subjects were feeling the week before. Each question has a set of four possible responses, ranging in intensity (0-3). A total score is computed reflecting the outcome index of depression. The validated Hungarian version of the short-form of the inventory with 13 items was completed by the respondents $[49,50]$.

To examine infertility-related distress with an infertility specific scale, the Fertility Problem Inventory (FPI) was included. FPI is a 46-item questionnaire developed to measure the level of infertility-related stress [51]. The scale consists of five subscales identifying the following domains: social concerns, sexual concerns, relationship concerns, rejection of childfree lifestyle and need for parenthood. Higher score indicates that the individual is experiencing more psychological stress than the average individual seen for infertility (85-98\% reflects moderately high stress, and above $98 \%$ reflects very high level of stress). The former Hungarian version [52] was accurately redefined, results will be published separately.

\section{Assessment of PA}

To describe PA and exercise habits, participants selfreported on the type and frequency of exercise in a PA diary and reported all kinds of physical activity in GPAQ-H. These self-reports were compared with objective measures collected by the Triaxial ActiGraph GT3X+ accelerometers.

\section{Global physical activity questionnaire (GPAQ-H)}

The GPAQ version 2 was used in our research, which was developed by the WHO. This self-administered form comprises 16 items that measure the physical activity levels of a typical active week (7 days) of adults. The questionnaire contains three domains of PA: work, transportation, and recreational activities. The duration and frequency of physical activity ( $\mathrm{min} /$ day) were recorded in case of all three above-mentioned domains. The evaluation of the intensity of certain activities is well introduced for the respondents in the questionnaires' manual, based on the extent of increase in breathing or heart rate [53]. Results were expressed in time (minutes) or in energy expenditure (MET: Metabolic Equivalent of Task). According to intensity, moderate and vigorous activities can be classified and walking activities should be also distinguished.

Our study indicates data in min/week format for easier comparison with accelerometer data. Total MVPA min/ week (all vigorous + all moderate activities' mins), moderate and vigorous activities in $\mathrm{min} /$ week, and weekly sitting time in min/week values were calculated $[53,54]$.

The cultural adaptation, efficient translation, and validation of the Hungarian version were composed by our research group [54-56]. A total of 120 healthy adults (age $21.53 \pm 1.75$ years, $46.66 \%$ male) were included in the validity and reliability study, their last 7 days PA by GPAQ-H was compared with IPAQ-Hungarian Long version and Actigraph GT3X accelerometer data at the University of Pécs. Although, the validity GPAQ-H was fair to moderate (MVPA $R=0.290, p=0.001$ ) but it was acceptable, as by similar European studies. Consequently, it could be claimed that the GPAQ-H proved to be a valid and reliable questionnaire to measure the healthy Hungarian general population's physical activity patterns [57].

For calculation of energy expenditure (MET) of PA following the guidelines of both of the questionnaires MPA by 4 MET, VPA by 8 MET and walking by 3.3 MET should be multiplied [53, 56, 58, 59]. We decided to apply the values of the updated "Physical Activity Guidelines for Americans", which calculates with 3, 6 and 2.5 METs respectively [60].

\section{Accelerometry monitoring}

Triaxial ActiGraph GT3X+ accelerometers (ActiGraph, Pensacola, FL) were used to collect data on PA with standard device initialization (sample rate of $30 \mathrm{~Hz}, 60 \mathrm{~s}$ epochs and normal filter option).

Participants were instructed to wear the accelerometer on the right hip (near the iliac crest) for a week, from the time they woke up in the morning until they retreated at the end of the day, except for the duration of any water-based activities, such as swimming or bathing. The Actigraph GT3X + device measures the strength of the movement in three spatial directions, as well as their duration. The device converts acceleration into a quantifiable and measurable digital signal. It allows us to accurately assess daily activities and classifies it into categories.

Sixty or more motionless minutes were defined as "non-wear time". A minimum of $480 \mathrm{~min}$ of wear-time was required daily and a minimum of 5-7 days with valid wear-time including at least one weekend day was required for inclusion in the analysis [61]. Finally, all valid days of recording were averaged and multiplied by seven to provide the comparability with the questionnaires. 
ActiLife 6 software was used to initialize the accelerometer and to download results, and row data was converted with Freedson cut points [62]. The average of daily moderate to vigorous physical activity (MVPA) (min/day) and sedentary behaviour (SB) (min/day) was calculated [63], with a sensitivity and specificity of more than 98 and 99\%, respectively [64].

Based on the additional physical activity diaries, there were no contact sports or water-based activities performed, which may restrain the participants to wear the accelerometer. However, four participants were excluded due to invalid wear-time. The average number of valid days was 6.32 .

\section{Physical activity categories by guidelines}

Following the recommendation of the American Congress of Obstetricians and Gynaecologists (ACOG), pregnant women should engage in moderate intensity exercise for $150 \mathrm{~min}$ per week $[65,66]$. However, there are no definitive physical activity guidelines for women attempting conception, or before or during assisted reproduction treatment.

To interpret our results, physical activity was categorized by meeting the key values of Physical Activity Guidelines for Americans for adults as inactive (any activity beyond basic movement from daily life activities), insufficiently active (less than $150 \mathrm{~min}$ of moderateintensity physical activity (MPA) or 75 min of vigorousintensity physical activity (VPA) or the equivalent combination of them per week), active (equivalent of 150 min to 300 min of MPA a week), or highly active (more than $300 \mathrm{~min}$ of MPA a week) [60]. Equivalent values were calculated through doubling by vigorous values and added to moderates.

PAQs scoring protocols are focusing on cumulative values of PA performed on average weeks or the week prior to the measurement. GPAQ categorises the level of physical activity as High, Moderate or Low by summing total PA [53], whereas the PA guidelines of PAGAC and ACOG focus on aerobe or exercise-type PA in relation to health enhancing effects. Therefore, we decided to analyse our data using the recreational type of activities following the PAGAC and ACOG categories [60, 65, 66].

\section{Fertilization protocol}

Publications of the Human Reproduction Scientific Research Group by Bódis and Várnagy described the detailed protocol of fertility treatments [67-69]. Patient enrolment into IVF procedure was approved by two independent physicians. The fertilization was performed with traditional IVF or intracytoplasmatic sperm injection (ICSI) depending on the andrological status (sperm count less than $15 \mathrm{M} / \mathrm{ml})$, the maternal age (>35) and the number of the previous IVF cycles the patient had before $(>2)$. Only metaphase II oocytes, identified by the presence of the first polar body, were chosen for fertilization. Embryo transfers were done 3-5 days after the oocyte retrieval. Only Grade 1 staged embryos were transferred, according to the Consensus embryo scoring system of ESHRE. To evaluate the success of the treatment, transvaginal ultrasound examination was performed 21 days after the embryo transfer to detect gestational sac [67].

One patient was excluded due to high risk of implantation failure, in her 8 th cycle. The remaining patients took part in cycles $1-4$.

\section{Statistical analysis}

Statistical analyses were performed using IBM SPSS Statistics 25.0 for Mac (SPSS Inc., Chicago, IL, USA). Normality of data distribution was tested by KolmogorovSmirnov test. Mann-Whitney U-test was used to compare continuous variables. The association between two continuous variables was tested by Spearman's rank correlation. To define predicting factors of primary and secondary outcomes of IVF from pre-treatment habitual PA, psycho-socio-demographic and baseline biomedical variables, we conducted a multivariate linear regression using the stepwise method. Logistic regression analysis was conducted to evaluate the effects of all the above parameters on live births. A post-hoc statistical power analysis was performed using $\mathrm{G}^{*}$ Power software, version 3.1.9.6 for Mac (Franz Faul, Christian-AlbrechtsUniversität Kiel, Kiel, Germany) [70]. Data was expressed as mean \pm SD as well as medians with 25 th and 75 th percentiles and the significance level of $\mathrm{p}<0.05$ was considered in each case.

\section{Results}

\section{General and infertility-related distress}

The validated Hungarian short-form of the Beck Depression Inventory (BDI-13) was applied [44-47, 49, 50] to reflect on distress in general. $68.96 \%$ of the respondents scored less than 5 points, which indicates normal mood state; and $20.68 \%$ belonged to the category of mild depression (6-11 points). Two patients reported severe depression.

For the purpose of measuring the level of infertilityrelated stress, FPI was applied and moderately high Global stress $(183.33 \pm 28.19)$ was explored. In the five domains of the questionnaire we found similar values as in the pilot study [71]. Average stress by Rejection of childfree lifestyle $(23.25 \pm 6.04)$, moderately high stress by Social concern $(41.40 \pm 9.84)$ and very high stress level by Sexual- (38.62 \pm 7.77$)$ and by Relationship concern $(48.53 \pm 9.68)$. Stress related to Need for parenthood was low again, but markedly higher than in our first pilot 
study $(31.68 \pm 8.35$ vs $23.1 \pm 5.7)$. Table 2 shows these results.

\section{Descriptive analysis of physical activity patterns.}

Pre-treatment physical activity patterns of women undergoing ART were summarised in Additional file 1. Intensity, frequency and mode of PA were described using the GPAQ-H questionnaire and ActiGraph GT3X accelerometer.

Regarding GPAQ-H, respondents performed an average of $461.50 \pm 785.56 \mathrm{~min} /$ week moderate and $158.00 \pm$ $467.34 \mathrm{~min} /$ week vigorous PA in work and only $35.00 \pm$ $82.70 \mathrm{~min} /$ week vigorous activity in recreation/leisure time domain. However, medians $(0.00)$ revealed that vigorous PA during work or leisure time are not common in the studied group. They preferred moderate intensity recreational activities for $2 \mathrm{~h}$ per week $(124.80 \pm 339.56)$.

Nevertheless, they spent $268.75 \pm 521.77 \mathrm{~min} /$ week on average with active transportation, for example with walking or cycling, which covers $806.25 \pm 1565.30$ MET energy expenditure. Means significantly differed in these relations also, as only 120 min transportation was characteristic. They spent $6.53 \mathrm{~h}$ per day sedentary (2745.17 $\pm 1755.39 \mathrm{~min} /$ week).

Analysing the data by intensity, we found that respondents spent $786.32 \pm 998.92 \mathrm{~min} \quad(2910.65 \pm 3932.02$ MET) with moderate to vigorous activities (MVPA). In total, considering all types and intensities of activities lasting more than $10 \mathrm{~min}$, women performed around $16.98 \mathrm{~h} \quad(1018.95 \pm 1225.72 \mathrm{~min} /$ week $) \quad$ or $3716.90 \pm$ 4588.16 MET PA.

Regarding the ActiGraphs, light activity was the most typical with $1239.87 \pm 329.50 \mathrm{~min} /$ week, moderate $(233.35 \pm 132.00 \mathrm{~min} /$ week $)$ and vigorous activities $(4.65 \pm 13.27 \mathrm{~min} /$ week) lag behind the subjective measures, very vigorous activity was almost negligible $(3.70 \pm 15.73 \mathrm{~min} /$ week $)$. They performed around $4 \mathrm{~h}$ MVPA (241.70 $\pm 145.10 \mathrm{~min} /$ week) and took in average

Table 2 Pre-treatment distress characteristics of women undergoing ART $(N=45)$

\begin{tabular}{llllll}
\hline BDI & & & & & \\
& Mean & SD & Median & IQR lower & IQR upper \\
General Stress & 4.92 & 4.82 & 4.00 & 1.00 & 8.00 \\
FPI & & & & & \\
Domains & Mean & SD & Median & IQR lower & IQR upper \\
Social Concern & 41.40 & 9.84 & 42.50 & 33.25 & 50.75 \\
Sexual Concern & 38.62 & 7.77 & 41.00 & 34.25 & 45.00 \\
Relationship Concern & 48.53 & 9.68 & 50.00 & 42.00 & 57.00 \\
Rejection Concern & 23.25 & 6.04 & 23.00 & 18.00 & 28.00 \\
Need for Parenthood & 31.68 & 8.35 & 31.00 & 28.00 & 37.00 \\
Global Stress & 183.33 & 28.19 & 179.50 & 165.00 & 202.50 \\
\hline
\end{tabular}

7060.28 steps daily $(49,422.73 \pm 16,351.52$ counts/week $)$ based on objective measures.

\section{Comparative analysis of physical activity patterns}

Comparing the data of the measurements, we found significant differences between the subjective instrument and the objective measures in all of the marked scores except for vigorous Accelerometer and GPAQ-H means $(p=0.255)$. (Table 3.)

To validate subjective PA results, we examined the correlation between accelerometer and questionnaires according to moderate, vigorous, MVPA activities, and sitting time values.

The GPAQ-H vigorous PA showed significant correlation with light accelerometer values $(R=0.310, p=$ 0.090). Time spent with transportation and the respective MET values showed moderate correlation with light activities $(R=0.506, p=0.004)$ a tendency-like relationship ( $R=0.349, p=0.055)$ with objectively measured weekly steps, yet moderate negative correlation with sedentary time $(R=-0.511, p=0.003)$.

If we categorise their performance, 27 women (60.00\%) reported notable leisure time PA, and only 18 of them $(40.00 \%)$ reached the $150 \mathrm{~min} /$ week RMPA recommendation. $9(20.00 \%)$ persons spent more than 240 $\mathrm{min} /$ week with recreational type PA, just like in the PAGA Highly active category. Comparison of pretreatment physical activity characteristics of women undergoing IVF by physical activity categories is presented in Table 4.

\section{Relationship between psychosocial distress aspects and PA} Relationship between generic PSD, measured with BDI and PA patterns was not found. Our results on GPAQ$\mathrm{H}$ revealed that recreational PA could counteract with some aspects of infertility related distress, since time spent with moderate RPA, total time and total MET of RPA negatively correlated with Social Concern $(R=$ $-0.378 p=0.013, R=-0.386 p=0.012$ and $R=-0.360 p=$ 0.023 respectively) and Relationship Concern of FPI $(R=-0.365 p=0.019, R=-0.368 p=0.018$ and $R=-0.342$ $p=0.033$ respectively). However, time spent with vigorous RPA was also significantly correlated to 'Rejection of

Table 3 Comparison of pre-treatment physical activity characteristics of women undergoing IVF based on accelerometer, self-administered GPAQ-H questionnaires and ActiGraph GT3X mean values difference

\begin{tabular}{lll}
\hline Intensity & $\mathbf{p}$ & $\begin{array}{l}\text { Mean Difference } \\
(\mathbf{m i n} / \text { week })\end{array}$ \\
\hline Sedentary & 0.000 & -5980.21 \\
Moderate & 0.002 & 626.75 \\
Vigorous & $\mathbf{0 . 2 5 5}$ & 184.06 \\
MVPA & 0.001 & 805.23 \\
\hline
\end{tabular}


Table 4 Comparison of pre-treatment physical activity characteristics of women undergoing IVF $(N=45)$ by physical activity categories

\begin{tabular}{|c|c|c|c|c|c|}
\hline & \multicolumn{5}{|c|}{ Physical Activity Categories } \\
\hline & Inactive & Insufficiently active & Active I & Highly active & Total \\
\hline Groups & $0 \mathrm{~min} /$ week & $\leq 149 \mathrm{~min} /$ week & 150-299 min/week & $\geq 300 \mathrm{~min} /$ week & \\
\hline \multirow[t]{3}{*}{ Non-pregnant } & 14 & 6 & 4 & 8 & 32 \\
\hline & $43.75 \%$ & $18.75 \%$ & $12.50 \%$ & $25.00 \%$ & $100.00 \%$ \\
\hline & $77.78 \%$ & $66.67 \%$ & $44.44 \%$ & $88.89 \%$ & $71.11 \%$ \\
\hline \multirow[t]{3}{*}{ Pregnant } & 4 & 3 & 5 & 1 & 13 \\
\hline & 30.77 & 23.08 & 38.46 & 7.69 & $100.00 \%$ \\
\hline & $22.22 \%$ & $33.33 \%$ & $55.56 \%$ & $11.11 \%$ & $28.88 \%$ \\
\hline \multirow[t]{3}{*}{ Total } & 18 & 9 & 9 & 9 & 45 \\
\hline & $40.00 \%$ & $20.00 \%$ & $20.00 \%$ & $20.00 \%$ & $100.00 \%$ \\
\hline & $100.00 \%$ & $100.00 \%$ & $100.00 \%$ & $100.00 \%$ & $100.00 \%$ \\
\hline
\end{tabular}

childfree lifestyle' $(R=0.354 p=0.021)$. A relationship similar to the above cannot be described by ActiGarph.

\section{Relationship between IVF outcomes and physical activity}

If we divided IVF patients regarding the presence of clinical pregnancy, we can conclude that PA patterns differ. Due to high SD, significant difference was detected only in case of GPAQ-H recreational PA MET means ( $p=$ 0.048). Minutes spent with recreation per week also showed slight difference, but a level of significance was not reached $(p=0.067)$. In both cases, means of the pregnant group were higher.

If the tendencies were analysed by the subjective and objective measures, it could be seen that pregnant women spent more time and energy expenditure prior to the treatment with recreational type- or with vigorous activities, which refers to exercise. In contrast, in the non-pregnant group cumulative values of PA were higher, but in relation to work or in total, we assume that the amount of PA alone did not have a positive effect. Type and intensity of PA seems to be significant. (Additional file 2).

Consistent with the above results, if the pre-treatment PA measures undergoing IVF/ICSI were analysed by secondary outcomes, correlations can only be found with time spent with recreation. Significant relationship was found with the number of retrieved oocytes $(R=0.315$, $p=0.045)$, number of matured oocytes $(R=0.339, p=$ $0.030)$ and slight trend with Grade 1 embryos $(R=0.294$, $p=0.062$ ) by women who reached at least $150 \mathrm{~min}$ RPA measured by GPAQ-H.

\section{Multivariate linear regression analysis}

To define predicting factors of primary and secondary outcomes of IVF from pre-treatment habitual PA, psycho-socio-demographic variables, and baseline biomedical variables, we conducted multivariate linear regression using the stepwise method.

We applied 3 models, which included women's age, education, BMI, child-wish, duration of infertility and number of cycles, QoL and PSD parameters, and PA values as covariates. In the first step, we adjusted for age, education, and BMI. In the second step child-wish, duration of infertility and number of cycles were additionally adjusted. In the third step, we adjusted subscales of BDI and FPI as well, and finally, in the fourth step PA parameters as GPAQ-H and ActiGraph data were also included.

In Model $1\left(R^{2}=0.367\right)$ the number of oocytes, as the dependent variable was influenced positively by the GPAQ-H recreation MET $(F=10.994, p=0.004 ; \quad \mathrm{B}=$ $0.005, p=0.004$, B Constant $=4.604)$.

The number of Grade 1 embryos was also examined as a dependent variable in Model $2\left(R^{2}=0.757, \mathrm{~F}=17.692\right.$, $p<0.001$, B Constant $=1.342$ ). Positive significant relationship was found with GPAQ-H recreational physical activity MET $(\mathrm{B}=0.004, p<0.001)$ and negative relationship with BMI $(B=-0.167, p=0.038)$.

When hCG levels on day 12 were considered as a dependent variable, multivariate linear regression disclosed in Model $3\left(R^{2}=0.0 .958, F=408.479, p<0.001\right)$ that higher Very Vigorous Activity level measured with ActiGraph was accompanied with higher hCG levels $(\mathrm{B}=63.703, p \leq 0.001)$.

\section{Logistic regression analysis}

On the basis of biomedical, psycho-socio-demographic and PA variables, logistic regression analysis was conducted to evaluate the effects of all the above parameters on live births. Contrary to our previous findings, the results indicated that total time (min/week) spent with moderate PA measured with GPAQ (beta coefficient $[B]=0.002$, standard error $[S E]=0.001$, Wald $=3.944$, 
$p=0.047, \mathrm{OR}=1.002)$ significantly associated with live births.

\section{Discussion}

It was assumed that the abundance of pre-treatment PA would decrease psychosocial distress domains in ART patients and thereby enhance reproductive performance. To assess the effects of psychosocial and lifestyle factors with special regard to physical activity on course and success of ART an observational cohort study was conducted with a follow-up of primary and secondary outcomes. To the best of our knowledge the current study was the first one in Hungary which gave a detailed description on the physical activity patterns of the specific cohort of patients undergoing assisted reproductive treatment using ActriGraph GT3X accelerometers and GPAQ-H questionnaire.

In general, $68.96 \%$ of the studied sample reported normal mood state (BDI-13), however they could be characterised by moderately high infertility-related distress (FPI), with moderately high level by Social- and very high level by Sexual concern.

Relationship between generic PSD, measured with BDI and PA patterns cannot be described. Our GPAQ-H results revealed that recreational PA could counteract with some aspects of infertility related distress, RPA negatively correlated with Social Concern and Relationship Concern of FPI. Significant difference cannot be described using PAGA PA categories or the $240 \mathrm{~min}$ cut off point regarding PSD.

Comparison of fertility-specific and general questionnaires can be found in literature in relation to ART patients [72-74]. Cserepes et al. conducted research using FertiQoL and Beck Depression Inventory on a Hungarian sample (126 couples). Female members of the couples reported poorer QoL than males. Subscales of the Core module scored between 69.01 \pm 16.33 (Emotional Scale) and $80.26 \pm 13.85$ (Social scale), total QoL was described as $77.27 \pm 12.05$. These values were markedly higher than in our sample [75].

Domar et al. underline the role of improving mental health with psychological interventions in improved pregnancy rates among infertile women [76]. Other studies shift focus to lifestyle behaviours: Domar et al. made surprising observations regarding interfering health behaviours as exhausting exercise, smoking, regular consumption of alcohol and caffeinated beverages and taking herbal supplements during IVF cycles [77]. In our sample more health-conscious lifestyle could be observed.

The Fertility Experiences Project examined 202 first IVF cycle patients to predict the influence of psychological distress on IVF treatment outcome and subsequent PSD, in a prospective cohort study over an 18- month period using the Epidemiologic Studies Depression Scale (CES-D) and the State Anxiety Subscale of the State-Trait Anxiety Inventory (STAI). In a binary logistic model including covariates (woman's age, ethnicity, income, education, parity, duration of infertility, and time interval), pre-treatment depression and anxiety were not significant predictors of the outcome measures. In linear regression models including covariates (woman's age, income, education, parity, duration of infertility, assessment point, time since last treatment cycle, and pre-IVF depression or anxiety), experience of a failed IVF were associated with higher post-IVF depression and anxiety, which draw attention to the support of patients to prepare for and cope with treatment and treatment failure [78].

Regarding the examination of PA patterns, PAQs routinely overestimated all types and intensity of PA, but showed moderate correlation with objective values. Selfreported time spent sedentary was strongly correlated with questionnaires and accelerometer measures. Cumulative values of PA in average were analogous to the Hungarian general population, but medians demonstrated that most of these women completely avoided vigorous forms of PA and showed pre-treatment PA patterns like women during pregnancy.

Compared to the general Hungarian population, the subpopulation of the studied women cannot be described as inactive, however only $60.00 \%$ of the sample examined reported notable leisure time PA and only $40.00 \%$ reached the recommended level of $150 \mathrm{~min} /$ week recreational moderate physical activity. They spent $16.98 \mathrm{~h}$ per week with all forms of activity and spent $6.53 \mathrm{~h}$ per day sedentary. $50.00 \%$ of the women in the sample reported regular exercise, which could be considered as a relatively active subpopulation in Hungary compared to previous national studies [79, 80]. However, Ács et al. reported 10\% improvement in PA habits based on representative Eurobarometer data from 2018: Hungarians' regular sport participation and physical activity is $33 \%$, which is below the EU average (40\%). Authors noted that $42 \%$ of Hungarian citizens spent more than 2.5 and less than $5.5 \mathrm{~h}$ sedentary. With $6.53 \mathrm{~h}$ daily sitting time $(2745.17 \pm 1755.39 \mathrm{~min} /$ day $)$, our results are slightly elevated but are in line with the above findings [81].

The amount of PA in our research increased unexpectedly in line with age and also with BMI, suggesting a more health-conscious behaviour by women exposed to higher risk. The current study did not include questions on health literacy, so we can only assume that these participants had some supposed knowledge on the relationship between reduced conception rate and overweight/ obesity, insulin resistance or amount of visceral fat. Lungren, Kiel and co-authors developed a study protocol 
to provide knowledge on the results of a high-intensity interval training before ART in subfertile overweight or obese women and include the program in regular fertility care [82]. Similarly to other studies emphasizing the importance of PA on BMI [34], in a randomised controlled pilot trial authors proved, that the high-intensity interval training significantly improved insulin sensitivity, VO2 peak and abdominal fat. However, due to low number of participants (intervention group $N=8$, control group $N=10$ ) they could not draw a conclusion on pregnancy rate [82].

"Walking the way to better health" general recommendations promote 10,000 steps daily [83, 84]. With 7060.28 steps per day measured with accelerometers, our respondents cannot be categorised as inactive compared to a Nature letter by Althoff et al. on worldwide activity inequality, which mentioned the average daily steps to be around 5300 in Hungary, 5000 Worldwide and 4800 in the US, measured with smartphones [85]. In an update published in ACSM's journal, Medicine \& Science in Sports \& Exercise authors revealed that 70009000 steps per day may trigger in health benefits, which are associated with current public health guidelines' emphasis on minimal amounts of time spent in MVPA, the federally recommended amounts of 150 to $300 \mathrm{~min}$ per week [86].

Women were divided as per the abundance of clinical pregnancy. Pregnant women spent more time and energy expenditure with recreational type- or with vigorous activities, which refers to exercise. In contrast, in the non-pregnant group cumulative values of PA were higher, but in relation with work or in total, we assume that this alone did not have a positive effect. Type and intensity of PA seems to be significant. Significant relationship could be described with the number of retrieved oocytes, number of matured oocytes and sligth relationship with Grade 1 embryos by women who reached at least 150 min RPA measured by GPAQ-H.

It could be claimed that the GPAQ-H measurement tool is a valid and reliable questionnaire to measure the healthy Hungarian general population's physical activity patterns [57]. By the validation study of GPAQ-H, Bland Altman plots revealed mean differences between the GPAQ-H and accelerometer data. The plots showed that GPAQ-H overestimates vigorous activities by 212.75 min/week (331.82-757.42) and MVPA values by 104.93 min/week (-1016.98-807.11). In our current study we observed similar overestimation of vigorous activities with 331.10 vs $184.06 \mathrm{~min} /$ week, and considerable overestimation of MVPA 481.37 vs $805.23 \mathrm{~min} /$ week in case of GPAQ-H and IPAQ-SFH. In the validation study a high difference, $6336.79 \mathrm{~min} /$ week (CI 3638.18-9035.40) was revealed regarding sitting, as GPAQ-H largely underestimated the time spent sedentary [57].. Our study also revealed a difference in the measurement of sitting time between accelerometer and GPAQ-H $5980.21 \mathrm{~min} /$ week.

Regarding GPAQ, our respondents performed moderate intensity PA during work and preferred that during recreation. However, mean values showed some vigorous activity in work $(158.00 \pm 467.34 \mathrm{~min} /$ week $)$ and recreation $(35.00 \pm 82.70 \mathrm{~min} /$ week). Medians demonstrated that most of these women completely avoided vigorous forms of movement. Regarding female reproduction, there is a wide consensus on the beneficial effects of PA on gestation. Most studies draw attention to the risk of frequent vigorous PA on fertility $[87,88]$ and on success of ART [43, 77].

To describe PA levels, both instrumental and selfreported studies were published. Evenson et al. discussed that the adjusted odds of intrauterine gestation are higher among IVF patients who had higher continuous active living (OR 1.96, 95\% CI 1.09-3.50), sports/exercise (OR 1.48, CI 1.02-2.15), and total activity (OR 1.52, 95\% CI 1.15-2.01) indices in the past year [89].

Regarding the benefits of pre-treatment activity, Moran et al. reported positive effect of lifestyle intervention including exercise and diet in conjunction with ART in overweight and obese women and described elevated successful pregnancy rate $(12 / 18$ vs $8 / 20)$ in the intervention group compared to controls (Moran, Tsagareli, Norman, \& Noakes, 2011).

Palomba et al. in their observational cohort study assessed the relationship between RPA and reproductive performance in connection with lifestyle interventions in obese infertile women who received ART $(N=216)$. Number of pregnancies $(16 / 41,39.0 \%$ versus $28 / 175$, $16.0 \%$, respectively; $p=0.002)$ and live births $(10 / 41$, $24.4 \%$ versus $13 / 175,7.4 \%$, respectively; $p=0.004$ ) were significantly higher in 41 obese patients who did regular physical activity compared to 175 obese controls who did not. After adjusting for confounders, the relative risks for a clinical pregnancy and live birth were 3.22 (95\% CI 1.53-6.78; $P=0.002$ ) and 3.71 (95\% CI 1.519.11; $P=0.004)$ in active patients, and RPA significantly correlated with improved reproductive performance irrespective of bodyweight loss [40]. In our study we could conclude significant difference between pregnant and non-pregnant groups by GPAQ-H recreational PA MET means $(p=0.048)$, which underline the importance of leisure time activities (inter alia) against PA in general.

On the other hand, adverse effects of excessive PA are also demonstrated. Gudmundsdottir et al. found that women who are active on most days, tended to experience fertility problems 3.2 times more often. In this study exercising to exhaustion also led to 2.3 times more fertility impairments than low intensity PA [90]. Based on the data by Morris et al. on lifetime exercise (level of 
evidence: II-2), exercising $4 \mathrm{~h}$ or more per week indicate $40 \%$ less likelihood of having a live birth (OR 0.6, CI $0.4-0.8$ ), it is 3 times more likely to lead to cycle cancellation and 2 times more likely to lead to implantation failure or pregnancy loss (OR 2.8, CI 1.5-5.3; OR 2.0, CI 1.4-3.1; OR 2.0, CI 1.2-3.4 respectively) compared to non-exercise [43]. In the current research during the follow-up of IVF outcomes, particular attention was given to the women in our sample who reported at least $4 \mathrm{~h}$ exercise weekly (18.2\%). In our study neither negative nor positive effects can be concluded by exceeding 240 or even $300 \mathrm{~min}$ of activity per week. Significant relationship could be described in relation to reproductive performance (number of retrieved oocytes and number of matured oocytes) by women who reached at least $150 \mathrm{~min}$ pre-treatment RPA measured by GPAQ-H.

Positive effects were also concluded in the metaanalysis of eight published studies $(N=3683$ infertile couples) of Rao et al., which reported an increasing but not statistically significant trend in the implantation rate for physically active women when compared with physically inactive women $(\mathrm{OR}=1.95,95 \%$ CI 0.99-3.83, I $2=77 \%$ ). Rates of clinical pregnancy and live births in physically active women were significantly higher than those in physically inactive women $(\mathrm{OR}=1.96,95 \% \mathrm{CI}$ $1.40,2.73, \mathrm{I} 2=42 \%$ and $\mathrm{OR}=1.95,95 \%$ CI $1.06-3.59$, I $2=82 \%$, respectively) [41].

Regarding PA immediately after IVF, Evenson et al. could not find any association between accelerometermeasured activity or sedentary behaviour with IVF outcomes. They described that after embryo transfer women engaged only in light activity (ME $3.0 \mathrm{~h} /$ day) and sedentary behaviours (ME $9.0 \mathrm{~h} /$ day). Although the current research focused on pre-treatment habitual PA, measurement of post-treatment PA in relation to QoL, PSD, and success rates could also offer research potential.

Espinós et al. reported in their meta-analyses based on 8 RCTs, that although lifestyle programmes improved pregnancy rates (RR: 1.43, CI: 95\% 1.02 to $2.01 ; \mathrm{I} 2=60 \% ; 8$ RCTs; $N=1098)$, they had no impact on live births (RR: $1.39, \mathrm{CI}$ : $95 \% 0.90$ to 2.14 ; $\mathrm{I} 2=$ $64 \%$; 7RCTs; $N=1034$ ) and increased risk of miscarriage in obese infertile women [91]. In our sample, positive association was found between moderate PA and live births and no relationship with the ratio of miscarriage.

An analysis of 121,744 women with failed first treatment revealed that age is a key predictor of failure to have a live birth following IVF as well as the risk of hindered performance, while increased duration of infertility is also associated with poorer outcomes at every stage [92]. Comparing our results to our models, we cannot confirm the emphasized importance of PSD and age on reproductive performance.

To define predicting factors of primary and secondary outcomes of IVF from the point of view of PA and PSD, we conducted a multivariate linear regression using the stepwise method. We applied 3 models, which included women's age, education, BMI, child-wish, duration of infertility and number of cycles and PSD parameters, and PA values as covariates. In Model 1 the number of oocytes was influenced positively by the GPAQ-H recreation MET, in Model 2 the number of Grade 1 embryos was positively correlated with GPAQ-H recreational physical activity MET and negatively with BMI. It was disclosed in Model 3 that higher Very Vigorous Activity level measured with ActiGraph was accompanied by higher hCG levels.

Gaskins and co-authors reported similar findings on maternal PA and sedentary behaviour in relation to ART's reproductive outcomes. They found no association between MVPA time or total MET and outcomes as probability of implantation, clinical pregnancy or live birth. However, specific leisure time activities (aerobics, rowing, exercising with ski or stair machine) were positively associated with live birth ( $\mathrm{p}$-trend $=0.02$ ).

\section{Limitations}

The limitations of the study include the sample's nonrepresentative nature. To avoid potential confounders, patients were carefully selected, but made the study population modest. Objective measurement of PA patterns cannot be conducted by all patients and complete medical record was also missing in a portion of patients.

A post-hoc sample size estimation (using $G^{*}$ Power for Mac version 3.1.9.6) for the multivariate linear regression analysis (significance set at $5 \%$, power set at 0.8 , effects size at 0.15 , and number of predictors at 2) showed that a total of 55 subjects would have been required to ensure adequate statistical power for analyses. The final sample of 45 subjects did not meet the sample requirements. Whereas the sample size was relatively suboptimal, given the limited study power, i.e. $71.84 \%$, to detect the difference in primary and secondary outcomes of ART.

Attention was drawn by Gaskins et al. to the use of intermediate outcomes of IVF as surrogates of women's reproductive performance [93]. Ongoing pregnancy has been considered as acceptable surrogate for live birth, as well as clinical pregnancy in or study. However, the major potential limitation of using ongoing pregnancies as the primary outcome of ART is the significant odds of pregnancy loss between the pregnancy confirmation and live birth.

For more impressive results on the effects of physical activity on the effectiveness of fertility programmes, a 
detailed objective assessment of physical activity, increased number of participants, and further examinations on outcome measures, with live birth's rate as end point are needed in a well-powered randomized controlled prospective study.

\section{Conclusion}

Infertility-specific scales could provide a more appropriate information on PDS of ART patients compared to general scales. GPAQ-H could be used as a valid measurement tool for mapping PA habits of ART patients, noting that the robust difference between objective and subjective measures (self-reports) of PA highlight the need to improve physical literacy of women undergoing ART.

Based on our results, recreation type of pre-treatment PA could positively influence domains of infertility related QoL and PSD during ART and improve reproductive performance in relation to primary and secondary outcomes. Existing differences in response to infertility due to PA suggest the need for the development of a specific intervention.

\section{Supplementary information}

Supplementary information accompanies this paper at https://doi.org/10. 1186/s12889-020-09522-7.

Additional file 1 Pre-treatment physical activity characteristics of women undergoing ART $(N=45)$ based on accelerometer, selfadministered GPAQ-H questionnaire and ActiGraph GT3X data.

Additional file $\mathbf{2}$ Mean differences of pre-treatment physical activity measures undergoing IVF/ICSI $(N=45)$ by primary outcome.

\section{Abbreviations \\ ACOG: American congress of obstetricians and gynaecologists; ART: Assisted reproductive therapy; BDI: Beck depression inventory; BMI: Body mass index; ESHRE: European society of human reproduction and embryology; FertiQol: Fertility quality of life tool; FPI: Fertility problem inventory; GPAQ- $\mathrm{H}$ : Global physical activity questionnaire-hungarian version; HADS: Hospital anxiety and depression; ICD-11: International classification of diseases 11th revision; ICSI: Intracytoplasmic sperm injection; IQR: Interquartile range; IUI: Intrauterine insemination; IVF: In-vitro fertilization; MVPA: Moderate to vigorous physical activity; MET: Metabolic equivalent of task; Ol: Ovulation induction; PAQs: Physical activity questionnaires; RCT: Randomized controlled trial}

\section{Acknowledgements}

Authors wish to thank the women who underwent ART for participating in the study at such a challenging time of their life.

\section{About this supplement}

This article has been published as part of BMC Public Health Volume 21 Supplement 1, 2021: Level and Determinants of Physical Activity in the V4 Countries - Part 2. The full contents of the supplement are available online at URL. https://bmcpublichealth.biomedcentral.com/articles/supplements/ volume-21-supplement-1.

\section{Authors' contributions}

All authors read and approved the final manuscript. VP conceived, designed and managed the study, MK, JB, ÁV and KL contributed to the study conceptualization and provided critical editorial input to the interpretation of the data, OM contributed to interpretation of the psychometric properties of the sample, BP and $\mathrm{MH}$ contributed in collection and analysis of participants anthropometric and accelerometer data, VP, PA and AM contributed to the data collection and analysis, and to the drafting and final editing of the manuscript.

\section{Funding}

The publication costs were funded by the Economic Development and Innovation Operational Programme GINOP 2.3.2-15-2016-00047 grant. The authors declare that the design of the study and collection, analysis, and interpretation of data and writing of the manuscript are independent of GINOP.

\section{Availability of data and materials}

The dataset supporting the conclusions of this article is available from the corresponding author on reasonable request.

\section{Ethics approval and consent to participate}

The ethical approval was granted for the study by Ethics Committee of University of Pécs (Nr. 6533). Participants were informed about the research aim and methods before signing the informed consent form. The investigation conforms to the principles outlined in the Declaration of Helsinki.

Consent for publication

Not applicable.

\section{Competing interests}

The authors declare that they have no competing interests.

\section{Author details}

${ }^{1}$ Faculty of Health Sciences, University of Pécs, Vorosmarty u. 4, Pécs 7621, Hungary. ${ }^{2}$ MTA-PTE Human Reproduction Scientific Research Group, University of Pécs, Édesanyák u. 17, Pécs H-7624, Hungary. ${ }^{3}$ Department of Obstetrics and Gynaecology, Medical School, University of Pécs, Édesanyák u. 17, Pécs H-7624, Hungary.

Received: 31 January 2021 Accepted: 1 February 2021 Published: 23 April 2021

\section{References}

1. Mascarenhas MN, Flaxman SR, Boerma T, Vanderpoel S, Stevens GA National, regional, and global trends in infertility prevalence since 1990: a systematic analysis of 277 health surveys. PLoS Med. 2012;9(12):e1001356.

2. Calhaz-Jorge C, De Geyter C, Kupka MS, de Mouzon J, Erb K, Mocanu E, Motrenko T, Scaravelli G, Wyns C, Goossens V. Assisted reproductive technology in Europe, 2013: results generated from European registers by ESHRE. Hum Reprod. 2017:32(10):1957-73.

3. De Geyter C, Calhaz-Jorge C, Kupka MS, Wyns C, Mocanu E, Motrenko T, Scaravelli G, Smeenk J, Vidakovic S, Goossens V, et al. ART in Europe, 2014 results generated from European registries by ESHREt: the European IVFmonitoring consortium (EIM)‡ for the European Society of Human Reproduction and Embryology (ESHRE). Hum Reprod. 2018;33(9):1586-601.

4. De Geyter C, Calhaz-Jorge C, Kupka MS, Wyns C, Mocanu E, Motrenko T, Scaravelli G, Smeenk J, Vidakovic S, Goossens V, et al. ART in Europe, 2015: results generated from European registries by ESHRE†. Hum Reprod Open. 2020;2020(1):hoz038. https://doi.org/10.1093/hropen/hoz038.

5. ESHRE. Annual Report 2017. Grimbergen: ESHRE; 2018.

6. McLaren JF. Infertility evaluation. Obstet Gynecol Clin N Am. 2012;39(4): 453-63.

7. Bernard A, Krizsa F: Generally about infertility. Modern diagnostic and therapy in infertility [A meddőségről általában In: Kaáli, S: A meddőség korszerű diagnosztikája és kezelése] Medicina Könyvkiadó, Budapest 2006.

8. WHO: Infecundity, infertility, and childlessness in developing countries. DHS Comparative Reports 2004, 9

9. World Health Organization. Reproductive health indicators: guidelines for their generation, interpretation and analysis for global monitoring. Geneva: WHO Press: 2006

10. WHO. World report on disability. Geneva: World Health Organization; 2011.

11. WHO. International statistical classification of diseases and related health problems: 11th revision (ICD-11). Geneva: World Health Organization; 2018. 
12. Rashidi B, Montazeri A, Ramezanzadeh F, Shariat M, Abedinia N, Ashrafi M. Health-related quality of life in infertile couples receiving IVF or ICSI treatment. BMC Health Serv Res. 2008;8:186.

13. Zurlo MC, Della Volta MFC, Vallone F. The association between stressful life events and perceived quality of life among women attending infertility treatments: the moderating role of coping strategies and perceived couple's dyadic adjustment. BMC Public Health. 2019;19(1):1548.

14. Sumera A, Raafay S, Ayesha MI, Faisal IK, Syed FA, Annum S, Syed F-U-H. Knowledge, perceptions and myths regarding infertility among selected adult population in Pakistan: a cross-sectional study. BMC Public Health. 2011;11:760

15. Reading AE, Chang LC, Kerin JF. Attitudes and anxiety levels in women conceiving through invitro fertilization and gamete intrafallopian transfer. Fertil Steril. 1989:52(1):95-9.

16. Greil AL. Infertility and psychological distress: a critical review of the literature. Soc Sci Med. 1997;45(11):1679-704.

17. Magiakou MA, Mastorakos G, Webster E, Chrousos GP: The hypothalamicpituitary-adrenal axis and the female reproductive system. In: Adolescent Gynecology and Endocrinology: Basic and Clinical Aspects. Volume 816, edn. Edited by Creatsas G, Mastorakos G, Chrousos GP; 1997: 42-56.

18. Ferin M. Stress and the reproductive cycle. J Clin Endocrinol Metab. 1999; 84(6):1768-74

19. Dobson H, Ghuman S, Prabhakar S, Smith R. A conceptual model of the influence of stress on female reproduction. Reproduction. 2003;125(2): $151-63$.

20. Lynch CD, Sundaram R, Maisog JM, Sweeney AM, Louis GMB. Preconception stress increases the risk of infertility: results from a couple-based prospective cohort studyuthe LIFE study. Hum Reprod. 2014;29(5):1067-75.

21. Boivin J, Takefman JE. Stress level across stages of in-vitro fertilization in subsequently pregnant and nonpregnant women. Fertil Steril. 1995;64(4): 802-10.

22. Luppa P, Muller B, Jacob K, Kimmig R, Strowitzki T, Hoss C, Weber MM Engelhardt D, Lobo RA. Variations of steroid-hormone metabolites in serum and urine in polycystic-ovary-syndrome after nafarelin stimulation evidence for an altered corticoid excretion. J Clin Endocrinol Metab. 1995; 80(1):280-8.

23. Smeenk JM, Verhaak CM, Eugster A, van Minnen A, Zielhuis GA, Braat DD. The effect of anxiety and depression on the outcome of in-vitro fertilization. Hum Reprod. 2001;16(7):1420-3.

24. Smeenk JM, Verhaak CM, Vingerhoets AJ, Sweep CG, Merkus JM, Willemsen SJ, van Minnen A, Straatman H, Braat DD. Stress and outcome success in IVF: the role of self-reports and endocrine variables. Hum Reprod. 2005; 20(4):991-6

25. WHO. Global action plan on physical activity 2018-2030: more active people for a healthier world. Switzerland: World Health Organization; 2018

26. Merom D, Sinnreich R, Aboudi V, Kark JD, Nassar H. Lifestyle physical activity among urban Palestinians and Israelis: a cross-sectional comparison in the Palestinian-Israeli Jerusalem risk factor study. BMC Public Health. 2012;12(1):90.

27. Acs P, Stocker M, Fuge K, Paar D, Olah A, Kovacs A. Economic and public health benefits: the result of increased regular physical activity. Eur J Integr Med. 2016;8:8-12.

28. Ács P, Stocker M, Oláh A. The determination of economic and public health benefits achievable by increasing regular physical exercise. Apstract Appl Stud Agribusiness Commerce. 2013;8(1):5-14.

29. Ács P, Prémusz V, Morvay-Sey K, Kovács A, Makai A, Elbert G. A sporttal, testmozgással összefüggésben lévő mutatók változása Magyarországon és az Európai Unióban az elmúlt évek eredményeinek nyomán. Sport és Egészségtudományi Füzetek. 2018;2(1):61-76.

30. Börjesson M, Hellénius $M$, Jansson E. FYSS - physical activity in the prevention and treatment of disease. Stockholm: Elanders; 2010

31. Fusz K, Tóth Á, Varga B, Rozmann N, Oláh A. Different work schedules of nurses in Hungary and their effects on health. Ideggyogy Sz. 2017;70(3-4): 136-9.

32. Szalai M, Szirmai A, Fuge K, Makai A, Erdelyi G, Premusz V, Bodis J. Special aspects of social support: Qualitative analysis of oncologic rehabilitation through a belly dancing peer support group. Eur J Cancer Care. 2017;26(6): 10.1111/ecc.12656. https://doi.org/10.1111/ecc.12656

33. Szalai M, Lévay B, Szirmai A, Papp I, Prémusz V, Bódis J. A clinical study to assess the efficacy of belly dancing as a tool for rehabilitation in female patients with malignancies. Eur J Oncol Nurs. 2015;19(1):60-5.
34. Ruiz-Montero PJ, Castillo-Rodriguez A, Mikalački M, Nebojsa C, Korovljev D. 24-weeks Pilates-aerobic and educative training to improve body fat mass in elderly Serbian women. Clin Interv Aging. 2014;9:243-8.

35. Fusz K, Pakai A, Kívés Z, Szunomár S, Regős A, Oláh A. Work schedules in the Hungarian health care system and the sleep quality of nurses. Orv Hetil. 2016;157(10):379-84.

36. Davies GA, Wolfe LA, Mottola MF, MacKinnon C. Joint SOGC/CSEP clinical practice guideline: exercise in pregnancy and the postpartum period. Can J Appl Physiol. 2003;28(3):330-41.

37. Russo LM, Nobles C, Ertel KA, Chasan-Taber L, Whitcomb BW. Physical activity interventions in pregnancy and risk of gestational diabetes mellitus a systematic review and meta-analysis. Obstet Gynecol. 2015;125(3):576-82.

38. Prémusz V, Makai A, Melczer C, Perjés B, Ács P, Bódis J, Lampek K, Várnagy A. Habituális fizikai aktivitás és életminőség összefüggése várandósság alatt a WHO Global Physical Activity Questionnaire alapján. Magy Noorv Lapja. 2018;81(6):343-50

39. Tendais I, Figueiredo B, Mota J, Conde A. Physical activity, health-related quality of life and depression during pregnancy. Cad Saude Publica. 2011; 27(2):219-28.

40. Palomba S, Falbo A, Valli B, Morini D, Villani MT, Nicoli A, La Sala GB. Physical activity before IVF and ICSI cycles in infertile obese women: an observational cohort study. Reprod BioMed Online. 2014;29(1):72-9.

41. Rao M, Zeng Z, Tang L. Maternal physical activity before IVF/ICSI cycles improves clinical pregnancy rate and live birth rate: a systematic review and meta-analysis. Reprod Biol Endocrinol. 2018;16(1):11.

42. Rich-Edwards JW, Spiegelman D, Garland M, Hertzmark E, Hunter DJ, Colditz GA, Willett WC, Wand H, Manson JE. Physical activity, body mass index, and ovulatory disorder infertility. Epidemiology. 2002;13(2):184-90.

43. Morris SN, Missmer SA, Cramer DW, Powers RD, McShane PM, Hornstein MD. Effects of lifetime exercise on the outcome of in vitro fertilization. Obstet Gynecol. 2006;108(4):938-45.

44. Beck AT, Ward CH, Mendelson M, Mock J, Erbaugh J. An inventory for measuring depression. Arch Gen Psychiatry. 1961;4:561-71.

45. Beck AT, Steer RA, Carbin MG. Psychometric properties of the Beck depression inventory: twenty-five years of evaluation. Clin Psychol Rev. 1988; 8(1):77-100.

46. Beck AT. Cognitive therapy of depression. New York: Guilford press; 1979.

47. Beck AT, Beck RW. Screening depressed patients in family practice. A rapid technic. Postgrad Med J. 1972;52(6):81-5.

48. Khademi A, Alleyassin A, Aghahosseini M, Ramezanzadeh F, Abhari AA. Pretreatment Beck depression inventory score is an important predictor for post-treatment score in infertile patients: a before-after study. BMC Psychiatry. 2005;5:25.

49. Kopp M, Fóris N. A szorongás kognitív viselkedésterápiája. Budapest: Végeken Sorozat; 1993.

50. Reynolds WM, Gould JW. A psychometric investigation of the standard and short form Beck depression inventory. J Consult Clin Psychol. 1981;49(2): 306-7.

51. Newton CR, Sherrard W, Glavac I. The fertility problem inventory: measuring perceived infertility-related stress. Fertil Steril. 1999;72(1):54-62.

52. Cserepes RE, Kollar J, Sapy T, Wischmann T, Bugan A. Effects of gender roles, child wish motives, subjective well-being, and marital adjustment on infertility-related stress: a preliminary study with a Hungarian sample of involuntary childless men and women. Arch Gynecol Obstet. 2013;288(4): 925-32.

53. Department of Chronic Diseases and Health Promotion Surveillance and Population-Based Prevention World Health Organization. Global Physical Activity Questionnaire (GPAQ) Analysis Guide V2. Geneva; 2012. [https:// www.who.int/ncds/surveillance/steps/GPAQ\%20Instrument\%20and\%2 OAnalysis\%20Guide\%20v2.pdf]. Accessed 02 Mar 2018.

54. Herrmann SD, Heumann KJ, Der Ananian CA, Ainsworth BE. Validity and reliability of the global physical activity questionnaire (GPAQ). Meas Phys Educ Exerc Sci. 2013;17(3):221-35.

55. Armstrong T, Bull F. Development of the World Health Organization global physical activity questionnaire (GPAQ). J Public Health. 2006;14(2):66-70.

56. Cleland CL, Hunter RF, Kee F, Cupples ME, Sallis JF, Tully MA. Validity of the global physical activity questionnaire (GPAQ) in assessing levels and change in moderate-vigorous physical activity and sedentary behaviour. BMC Public Health. 2014;14

57. Ács P, Betlehem J, Oláh A, Bergier B, Morvay-Sey K, Makai A, Prémusz V. Cross-cultural adaptation and validation of the global physical activity 
questionnaire among healthy Hungarian adults. BMC Public Health. 2020; 20(1):1056. https://doi.org/10.1186/s12889-020-08477-z.

58. Bull FC, Maslin TS, Armstrong T. Global physical activity questionnaire (GPAQ): nine country reliability and validity study. J Phys Act Health. 2009; 6(6):790-804.

59. The IPAQ group. Guidelines for data processing and analysis of the International Physical Activity Questionnaire (IPAQ)-short and long forms. 2005. [https://docs.google.com/viewer?a=v\&pid=sites\&srcid=

ZGVmYXVsdGRvbWFpbnxOaGVpcGFxfGd4OjEONDgxMDk3NDU1YWRIZTM]. Accessed 20 Jan 2018.

60. U.S. Department of Health and Human Services. Physical Activity Guidelines for Americans, 2nd ed. Washington, DC: Department of Health and Human Services; 2018

61. Trost SG, Owen N, Bauman AE, Sallis JF, Brown W. Correlates of adults' participation in physical activity: review and update. Med Sci Sports Exerc. 2002;34(12):1996-2001

62. Freedson PS, Melanson E, Sirard J. Calibration of the computer science and applications, Inc. accelerometer. Med Sci Sports Exerc. 1998;30(5):777-81.

63. Matthews CE, Ainsworth BE, Thompson RW, Bassett DR Jr. Sources of variance in daily physical activity levels as measured by an accelerometer. Med Sci Sports Exerc. 2002;34(8):1376-81.

64. Skotte J, Korshoj M, Kristiansen J, Hanisch C, Holtermann A. Detection of physical activity types using triaxial accelerometers. J Phys Act Health. 2014; 11(1):76-84.

65. ACOG. ACOG Committee Opinion No. 650: physical activity and exercise During pregnancy and the postpartum period. Obstet Gynecol. 2015;126(6): e135-42.

66. ACOG. ACOG Committee opinion. Number 267, January 2002: Exercise during pregnancy and the postpartum period. Obstet Gynecol. 2002;99(1):171-3.

67. Várnagy Á, Köszegi T, Györgyi E, Sulyok E, Prémusz V, Bódis J. Levels of total antioxidant capacity and 8-hydroxy-2'-deoxyguanosine of serum and follicular fluid in women undergoing in vitro fertilization: focusing on endometriosis. Hum Fertil. 2020;23(3):200-8.

68. Bódis J, Várnagy Á. Non-invazív vizsgálati lehetőségek az in vitro fertilizációs kezelés hatásfokának növelésére. Magy Noorv Lapja. 2015;78(5):226-31.

69. Gödöny K, Laki K, Várnagy Á, Kovács K, Sulyok E, Berenténé Bene J, Melegh $B$, Bódis J. Az in vitro fertilizáció sikerességét befolyásoló biomarkerek vizsgálata: a karnitin jelentősége. Egészség-Akadémia. 2014;5(4):247-53.

70. Faul F, Erdfelder E, Lang AG, Buchner A. G*power 3: a flexible statistical power analysis program for the social, behavioral, and biomedical sciences. Behav Res Methods. 2007;39(2):175-91.

71. Prémusz V, Makai A, Gács B, Nagy Á, Perjés B, Ács P, Lampek K, Várnagy Á. Preliminary study on pre-treatment physical activity and quality of life in infertility. Exerc Qual Life J. 2019;11(2):5-17.

72. Aarts JW, van Empel IW, Boivin J, Nelen WL, Kremer JA, Verhaak CM. Relationship between quality of life and distress in infertility: a validation study of the Dutch FertiQoL. Hum Reprod. 2011;26(5):1112-8.

73. Dural O, Yasa C, Keyif B, Celiksoy H, Demiral I, Yuksel Ozgor B, Gungor Ugurlucan F, Bastu E. Effect of infertility on quality of life of women: a validation study of the Turkish FertiQoL. Hum Fertil. 2016;19(3):186-91.

74. Boivin J, Takefman J, Braverman A. The fertility quality of life (FertiQoL) tool: development and general psychometric properties. Hum Reprod. 2011; 26(8):2084-91.

75. Cserepes RE, Korosi T, Bugan A. A meddőséggel összefüggő életminőség jellemzői magyar pároknál [Characteristics of infertility-specific quality of life in Hungarian couples]. Orv Hetil. 2014;155(20):783-8.

76. Domar AD, Gross J, Rooney K, Boivin J. Exploratory randomized trial on the effect of a brief psychological intervention on emotions, quality of life, discontinuation, and pregnancy rates in in vitro fertilization patients. Fertil Steril. 2015;104(2):440-451.e447.

77. Domar AD, Conboy L, Denardo-Roney J, Rooney KL. Lifestyle behaviors in women undergoing in vitro fertilization: a prospective study. Fertil Steril. 2012;97(3):697-701.e691

78. Pasch LA, Gregorich SE, Katz PK, Millstein SG, Nachtigall RD, Bleil ME, Adler NE. Psychological distress and in vitro fertilization outcome. Fertil Steril. 2012;98(2):459-64

79. Bácsné Bába É, Fenyves V, Szabados G, Pető K, Bács Z, Dajnoki K. Sport involvement analysis in Hungary, in the north great plain region. Sustainability. 2018;10(5):1629.
80. Gabnai Z, Müller A, Bács Z, Bácsné Bába É. The economic burden of physical inactivity at national level [a fizikai inaktivitás nemzetgazdasági terhei]. Egészségfejlesztés. 2019;60(1):20-30.

81. Ács P, Prémusz V, Morvay-Sey K, Kovács A, Makai A, Elbert G. Changes of sport and physical activity indicators in Hungary and in the European Union according to the results from recent years (A sporttal, testmozgással összefüggésben lévő mutatók változása Magyarországon és az Európai Unióban az elmúlt évek eredményeinek nyomán). Sport és Egészségtudományi Füzetek. 2018;2(1):61-76.

82. Lundgren KM, Romundstad LB, von During V, Morkved S, Kjotrod S, Moholdt T. Exercise prior to assisted fertilization in overweight and obese women (FertilEX): study protocol for a randomized controlled trial. Trials. 2016;17

83. Duncan MJ, Brown WJ, Mummery WK, Vandelanotte C. 10,000 steps Australia: a community-wide eHealth physical activity promotion programme. Br J Sports Med. 2018;52(14):885-6.

84. HHS USDoHaHS: The Physical Activity Guidelines for Americans, 2nd edition, Date Accessed 08/06, 2019, from In: Physical Activity Guidelines Advisory Committee; 2018.

85. Althoff T, Sosič R, Hicks JL, King AC, Delp SL, Leskovec J. Large-scale physical activity data reveal worldwide activity inequality. Nature. 2017;547(7663): 336-9.

86. Tudor-Locke C, Craig CL, Brown WJ, Clemes SA, De Cocker K, Giles-Corti B, Hatano $Y$, Inoue S, Matsudo SM, Mutrie N, et al. How many steps/day are enough? For adults. Int J Behav Nutr Phys Act. 2011:8(1):79.

87. Green BB, Daling JR, Weiss NS, Liff JM, Koepsell T. Exercise as a risk factor for infertility with ovulatory dysfunction. Am J Public Health. 1986;76(12):1432-6.

88. Wise LA, Rothman KJ, Mikkelsen EM, Sorensen HT, Riis AH, Hatch EE. A prospective cohort study of physical activity and time to pregnancy. Fertil Steril. 2012;97(5):1136-42.

89. Evenson KR, Calhoun KC, Herring AH, Pritchard D, Wen F, Steiner AZ. Association of physical activity in the past year and immediately after in vitro fertilization on pregnancy. Fertil Steril. 2014;101(4):1047-U1482.

90. Gudmundsdottir SL, Flanders WD, Augestad LB. Physical activity and fertility in women: the north-Trondelag health study. Hum Reprod. 2009;24(12): 3196-204

91. Espinós JJ, Solà I, Valli C, Polo A, Ziolkowska L, Martínez-Zapata MJ. The effect of lifestyle intervention on pregnancy and birth outcomes on obese infertile women: a systematic review and meta-analysis. Int J Fertil Steril. 2020;14(1):1.

92. Bhattacharya S, Maheshwari A, Mollison J. Factors associated with failed treatment: an analysis of 121,744 women embarking on their first IVF cycles. PLoS One. 2013;8(12):e82249.

93. Messerlian C, Gaskins AJ: Epidemiologic approaches for studying assisted reproductive technologies: design, methods, analysis and interpretation. Curr Epidemiol Rep 2017, 4(2):124-132.

\section{Publisher's Note}

Springer Nature remains neutral with regard to jurisdictional claims in published maps and institutional affiliations.

Ready to submit your research? Choose BMC and benefit from:

- fast, convenient online submission

- thorough peer review by experienced researchers in your field

- rapid publication on acceptance

- support for research data, including large and complex data types

- gold Open Access which fosters wider collaboration and increased citations

- maximum visibility for your research: over $100 \mathrm{M}$ website views per year

At $\mathrm{BMC}$, research is always in progress.

Learn more biomedcentral.com/submission 